\title{
Dispersed Systems in Heavy Crude Oils
}

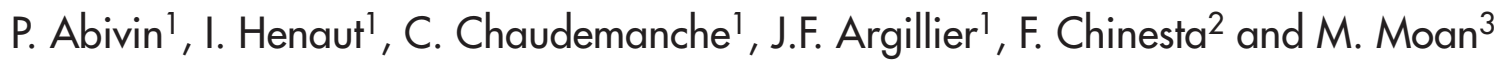 \\ 1 Institut français du pétrole, IFP, 1-4 avenue de Bois-Préau, 92500 Rueil-Malmaison Cedex - France \\ 2 ENSAM, 151 Bd de l'Hôpital, 75013 Paris - France \\ 3 UBO, Université de Bretagne Occidentale, 6 avenue Victor Le Gorgeu, 29238 Brest Cedex 3 - France \\ e-mail: patrice.abivin@ifp.fr - isabelle.henau†@ifp.fr - cyril.chaudemanche@ifp.fr - j-francois.argillier@ifp.fr - \\ francisco.chinesta@paris.ensam.fr-michel.moan@univ-brest.fr
}

\begin{abstract}
Résumé - Systèmes dispersés dans les bruts lourds - La diminution des ressources de pétrole conventionnel conduit les producteurs à orienter la recherche vers l'exploitation de bruts difficiles. Parmi ceux-ci, les bruts lourds, caractérisés par leur forte viscosité, constituent des réserves de pétrole abondantes. Des procédés particuliers tels que la production froide ou l'injection de vapeur permettent de récupérer ces bruts malgré leur forte viscosité. Lors de la production froide, l'huile peut avoir l'aspect d'une mousse que l'on nomme « foamy oil » : sous l'effet de la dépressurisation, certains éléments légers comme le méthane ou l'éthane peuvent passer à l'état gazeux sous forme de bulles. L'injection de vapeur implique, quant à elle, une production importante d'eau émulsionnée avec le brut. Le but de cet article est d'étudier l'influence de ces phases dispersées (gaz ou eau) sur les propriétés d'écoulement du brut dans les conditions de production (pression, température). À l'aide d'un procédé novateur, des mousses de brut lourd et des émulsions ont été reconstituées et leurs propriétés d'écoulement étudiées à l'aide d'un rhéomètre équipé d'une cellule sous pression. La première partie de l'article concerne la présence de bulles dans le brut lourd. Nous montrons qu'une forte déformation des bulles peut mener à une diminution significative de la viscosité de la mousse. En revanche, lorsque les bulles sont sphériques, elles contribuent à une augmentation de la viscosité du mélange. Dans la deuxième partie, les émulsions eau-dans-huile sont étudiées. De la même façon, sous une vitesse de cisaillement suffisamment élevée pour déformer les gouttes, on observe une diminution de la viscosité apparente de l'émulsion. La dernière partie décrit quelques essais qui combinent l'influence de la présence de bulles et de gouttes d'eau sur les propriétés d'écoulement des bruts lourds, se rapprochant des conditions réelles de production. Nous étudions notamment le rôle de la présence de gouttes d'eau sur le comportement moussant du brut. Finalement, ce travail expérimental montre que la viscosité des fluides de gisements dépend fortement des conditions de production et qu'il est essentiel d'en étudier le comportement rhéologique en fonction de la température, de la pression et de la présence de phases dispersées.
\end{abstract}

\footnotetext{
Abstract - Dispersed Systems in Heavy Crude Oils - Due to very large reserves, heavy crude oils represent an important challenge for the oil industry. Their production has to handle very viscous hydrocarbons and involves the use of advanced methods such as cold production or steam injection. Cold production is faced with the foamy oil phenomenon: while extracted, a heavy crude oil is submitted to a depletion that can induce the formation of dispersed gas bubbles and makes it appear as a foam. With steam injection, water is invariably produced and emulsions may be formed. These two situations show how heavy crude oils are concerned with dispersed systems. The aim of the article is to evaluate the impact of this dispersed phase, either bubbles or droplets, on the flow properties of heavy crude oils. To do so, measurements have been carried out with a controlled stress rheometer under pressure and temperature. Live samples were obtained by recombining a stock tank oil with methane inside the pressure cell of the rheometer. The first part of the article is dedicated to the foamy oil phenomenon. It
} 
demonstrates that contrary to spherical bubbles, deformed bubbles can give rise to significant viscosity reduction, which is governed by the capillary number. The second part deals with water-in-oil emulsions. Again, experimental results show that dispersed droplets increase viscosity unless they get sufficiently elongated by the applied shear rate. The last part of the article is particularly original as it studies some rheological experiments of heavy crude oils in presence of both gas bubbles and water droplets. It investigates to what extent the presence of water influences the bubbly characteristics of live heavy crude oils. The experimental work suggests that for optimum design and operations, it is essential to determine oilfield viscosities i.e. under pressure and temperature on live and changing dispersed systems.

\section{INTRODUCTION}

Because of very large reserves, heavy crude oils represent a challenge for the future. Indeed, the oil companies still have significant difficulties to produce these very viscous oils. Their rheological behavior appears as a key issue and has already been addressed (Coustet-Pierre, 2003). These results on pure heavy oils are of primary importance in the surface pipelines but in wells the influence of the gas and water that are co-produced should also be taken into account. Actually, the flow properties of the resulting multiphase mixture are much more complex than the ones of a single dead crude oil.

The pressure inside a crude oil reservoir results in a thermodynamic equilibrium between the gas cap, the lightest hydrocarbons (methane, ethane...) dissolved in the oil and the liquid crude oil. The amount of dissolved gas in this so-called "live oil" is proportional to the system pressure and obeys Henry's law: $[G]=H \times P$, where $H$ is Henry's constant, depending on both fluids, $P$ the pressure and $[G]$ the amount of dissolved gas. During its extraction and its transport from the reservoir to the wellhead, the live oil is depressurized. The equilibrium given by Henry's law is then broken, the live oil is supersaturated. To restore the equilibrium, the system tends to get rid of the excess of dissolved gas. So the depletion usually leads to the nucleation and growth of bubbles within the oil, what modifies its flow properties. In the case of light oils, bubbles coalesce very quickly and a slug flow can appear out of the well (Taitel, 1986; Henriot et al., 2002). On the opposite, in the case of heavy oils, bubbles remain dispersed and flow within the oil, what gives to the produced oil the aspect of a "chocolate mousse". This phenomenon, called "foamy oil phenomenon" (Smith, 1988; Maini et al., 1993), appears to cause higher production rates than expected by classical reservoir modelling (Smith, 1988; Huerta et al., 1996). Furthermore, favoring the foamy oil behavior is a technique used to enhance heavy oil recovery (Weatherhill et al., 2005). To understand it, several theories have been explored. One of them considers that bubbles trapped in the reservoir maintain a high pressure in the porous medium, what enhances the oil recovery (Renard et $a l ., 2000)$. Other theories suggest that the live oil viscosity is lower with the presence of bubbles, thus improving its transport in the well and the reservoir. For instance, it is proposed that asphaltenes migrate to the surface of bubbles (Bauget, 2002) and the resulted impoverishment of the matrix in asphaltenes decreases the foamy oil viscosity (Claridge and Prats, 1995). However, different experimental studies predict either an increase (Bora, 1998; Fisher et al., 1999; Goodarzi et al., 2005) or a decrease (Islam and Chakma, 1990; Albartamani, 2000) in the live oil viscosity with the presence of bubbles. The influence of bubbles on the heavy oil flow properties is thus still debated.

In addition to gas, water is invariably produced, leading most of the time to the formation of water-in-oil (W/O) emulsions. The presence of water is particularly encountered with the use of steam injection, process currently utilized for extra heavy oil production. These emulsions are not only stable due to natural surfactants (such as asphaltenes, naphtenic acids and resins) but also very viscous. Actually, their viscosity increases as the water content increases (Singh et al., 2004) up to the inversion point, where W/O emulsions are transformed into $\mathrm{O} / \mathrm{W}$ emulsions. In the field of heavy oil transportation, one way to reach low viscosities is thus to switch from $\mathrm{W} / \mathrm{O}$ to $\mathrm{O} / \mathrm{W}$ emulsions. A particular attention has been paid in the literature to the accurate determination of this inversion point (Szelag and Pauzder, 2003; Alboudwarej et al., 2007). Nevertheless, production rates higher than expected have been noticed (Loughead and Saltuklaroglu, 1992; Huerta et al., 1996), with low water-inoil ratio, far from the inversion point.

Thus heavy-oil production process gives rise to a complex dispersed system in which gas bubbles and water droplets flow within the oil, each of them affecting the apparent viscosity of the extracted fluid. The understanding of the flow properties of this multiphase mixture is fundamental to predict the performance of a production plant. So far, not many investigations have been devoted to these particular dispersions. The present work gradually addresses the problem of heavy oil flow properties in real conditions, i.e. with the presence of gas bubbles and water droplets. In the first part, the influence of gas bubbles on the viscosity of heavy oils is analyzed. It is followed in the second part by the study of the 
influence of water droplets on heavy-oil rheological behavior under field conditions. Finally, in the third part, some experiments performed on heavy oils containing both gas bubbles and water droplets are presented.

\section{FOAMY OIL PHENOMENON}

This section focuses on the foaming behaviour of heavy oils. Its purpose is to assess how the formation and the presence of bubbles can modify heavy oil viscosity. A new experimental approach has been developed to carry out this work. It consists in depleting different live oils in the pressure cell of controlled-stress rheometers. By measuring the viscosity and following the morphology of the created foam, the influence of bubbles on oil viscosity has been established. Particular attention has been paid to the role of shear rate, that in turn controls the shape of the bubbles.

\subsection{Materials and Methods}

The density of the Canadian heavy crude oil used in this study is 0.982 at $25^{\circ} \mathrm{C}$, its viscosity is $9 \mathrm{~Pa} . \mathrm{s}$ at $28.5^{\circ} \mathrm{C}$ and its asphaltene content is roughly 11 weight \% (determined by SARA analysis in heptane). We used two controlled-stress rheometers: Anton Paar Physica MCR 501 and TA Instruments AR2000. Both are fitted with a pressure cell (from 102 to $10 \mathrm{kPa}$ ). A schematic diagram of these experimental devices is presented in Figure 1. Magnetic transmission is used between the rheometer motor and the geometry. Pressure is applied to the sample by gas (either nitrogen or methane) and controlled by a pressure regulating valve.

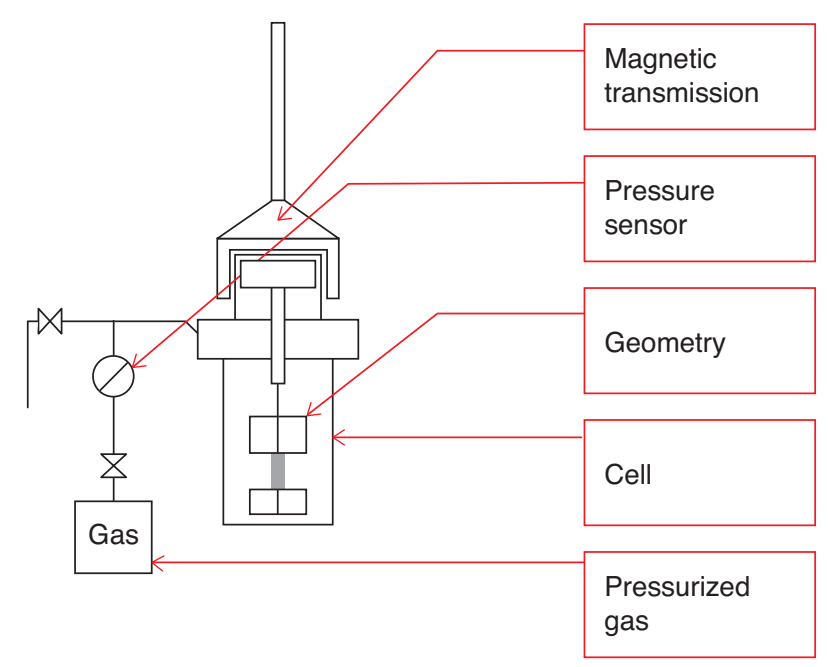

Figure 1

Scheme of the rheometer pressure cell.
Several geometries can be set: a vane, an helix or a Couettelike cylinder. We equally used the vane and the helix to avoid slipping effects and to improve the oil/gas mixing process. The Couette geometry is used to study the piezodependence of a liquid without dissolving any gas. The calculation of the viscosity is based on the Couette analogy (Ait-Kadi, 2002).

The experiments are divided into two steps. First, the live oil is prepared by introducing gas into the dead oil under pressure and shear $\left(100 \mathrm{~s}^{-1}\right)$. The gas slowly dissolves in the oil until the system reaches the equilibrium given by Henry's law. Mixing is very important during the process: the best the mixing, the fastest the system reaches the thermodynamic equilibrium, i.e. saturation. Using the helix and the vane devices, this process is a few hours long and is impossible with a classic Couette geometry. During this operation, the viscosity is continuously measured and drops with the dissolution of gas. The live oil is considered as saturated when the viscosity is stabilized. The gas dissolution conditions were the same for all the samples: 30 bars in methane. The amount of dissolved gas has been measured using PVT cells and approximately corresponds to a GOR (Gas Oil Ratio, ratio between gas volume and oil volume at room pressure and $15^{\circ} \mathrm{C}$ ) of 6 . During the second step, the live oil is depressurized from the saturation pressure to atmosphere. Again, the viscosity of the system is continuously measured under a constant shear rate during and after the depletion.

\subsection{Results on Heavy Crude Oil}

Depletions of live heavy crude oils have been performed both in quiescent and dynamic conditions. They lead to drastically different results that are successively described below.

\subsubsection{Depletion Under an Oscillatory Shear}

The first rheological experiments have been done in quiescent conditions with oscillatory tests, i.e. very low strain $(5 \mathrm{~Hz}$, $2 \%$ ), on the Canadian heavy oil saturated in methane (30 bars). These tests allow to study the viscoelastic behaviour of the foamy oil without any deformation of the bubbles. Indeed, under these conditions, they remain spherical. Figure 2 depicts the evolution of the corresponding complex viscosity after the depletion. We plotted the viscosity ratio which is defined as the ratio between the live oil viscosity and the oil viscosity without dissolved gas. As a result, the equilibrium value is 1 , which corresponds to the viscosity ratio when the oil has got rid of all the dissolved gas thermodynamically in excess at room pressure. At $t=0$, the viscosity ratio is less than 1 because the dissolved gas, like diluents, reduces the live oil viscosity. After the depressurization, the behavior of the live oil viscosity can be described into three steps (Fig. 2b). First, the viscosity declines drastically due to the pressure drop. 

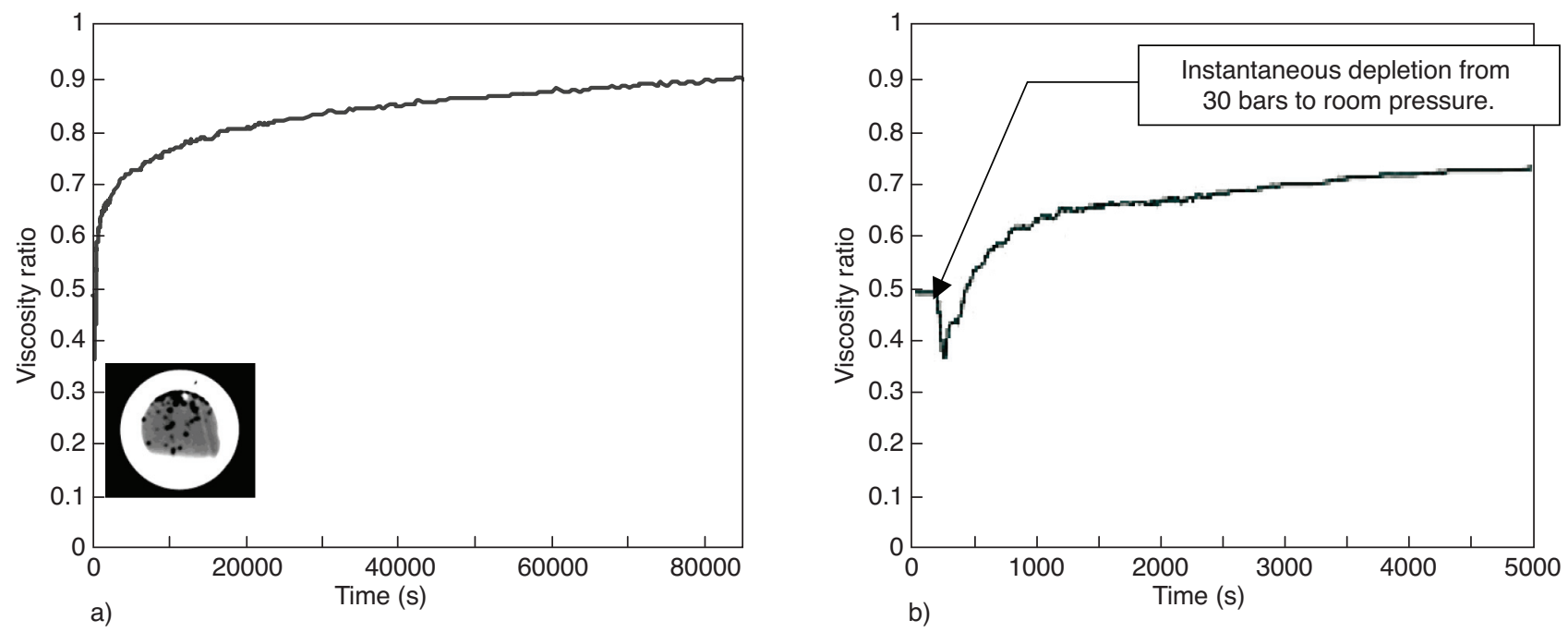

Figure 2

Evolution of the viscosity ratio of a Canadian heavy oil saturated in methane (30 bars) and depressurized from 30 bars to room pressure instantaneously. a) X-Ray picture taken 30 seconds after the depressurization. b) Zoom on the first minutes.

This is resulting from the high pressure-dependence of heavy oil viscosity (Abivin et al., 2008). Then, the viscosity rises quickly, then slowly to finally tend to the thermodynamics equilibrium. The occurrence of bubbles after the depressurization has been checked using X-Ray experiments (Fig. 2a). The degassing kinetics of different heavy oils has been studied in a previous paper (Abivin et al., 2008), in which a kinetics model of degassing live heavy oil viscosity is developed. To match this model with the experiments, Eintein's hard-sphere model (Einstein, 1906, 1911) was used to describe successfully the impact of bubbles on the viscosity of the foamy oils. This study confirmed that the presence of spherical gas bubbles leads to an increase in apparent foamy oil viscosity.

\subsubsection{Depletion Under Shear}

Opposite to these oscillatory tests, the same kind of experiments was carried out under different continuous shear rates. Figure 3 depicts the evolution of the Canadian heavy oil viscosity saturated in methane (30 bars) under shear rates of 10,50 and $100 \mathrm{~s}^{-1}$. The complex viscosity discussed above is also plotted for comparison. Two observations have to be pointed out. First, it appears that the higher the shear rate, the lower the viscosity ratio. Second, the viscosity seems to stabilize. It should also be noted that the kinetics model used in our previous paper do not match these new experimental results and overestimate the apparent viscosity of the mixture in all cases. As the model was made under the assumption that the bubbles are spherical (use of Eintein's hard sphere model), it seems that this hypothesis is no more valid and that bubbles are probably deformed by shear rate.
The decreasing apparent viscosity of a bubbly material below the viscosity of the material itself has already been observed for viscous fluids like magmas or melt glass and polymers (Manga and Loewenberg, 2001; Llewellin et al., 2002; Rust and Manga, 2002; Stein and Spera, 2002; Bagdassarov and Pinkerton, 2003; Tuladhar and Mackley, 2005). These studies have shown that this behaviour is due to

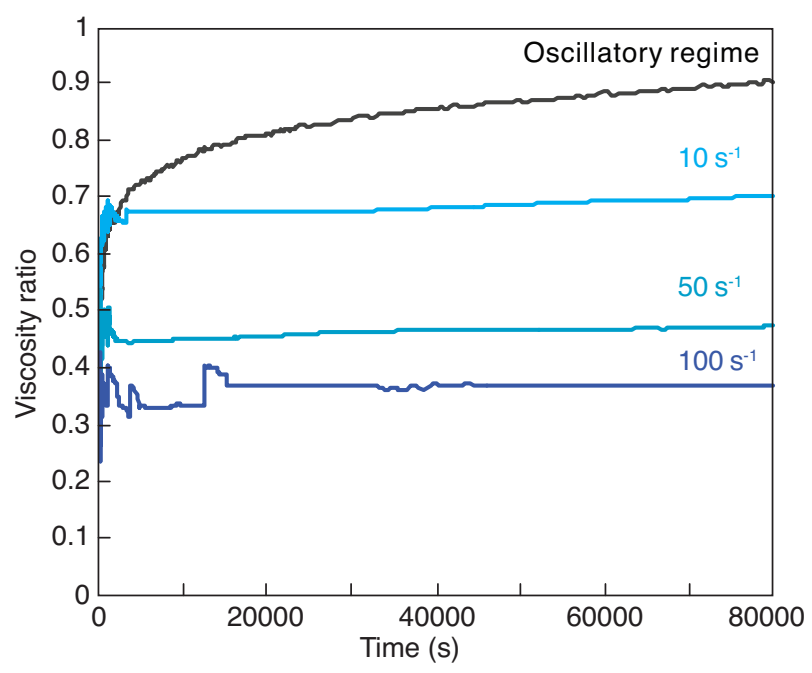

Figure 3

Viscosity ratio of a Canadian heavy oil saturated in methane and depressurized instantaneously from 30 bars to room pressure at different shear rates. 


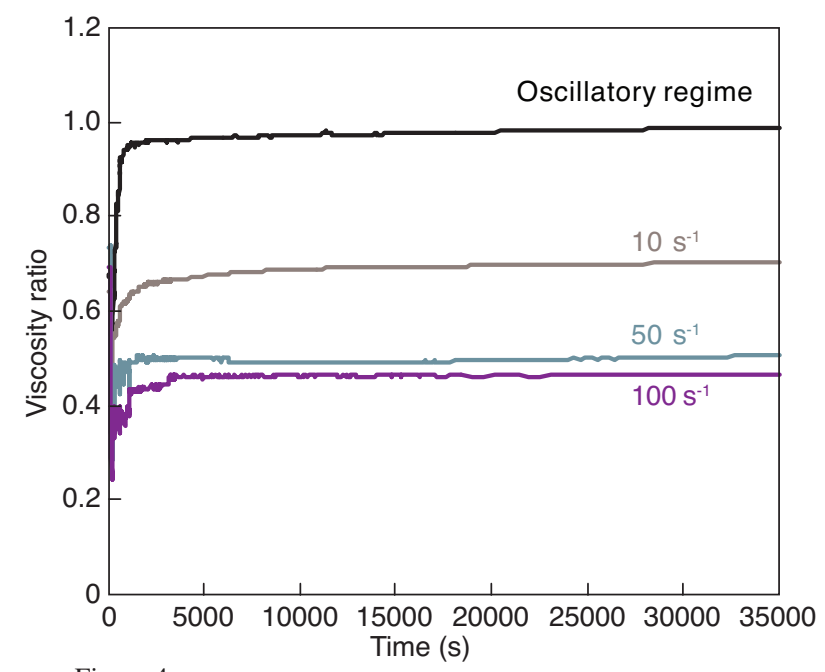

Figure 4

Viscosity ratio of a silicon oil saturated in methane and depressurized instantaneously from 30 bars to room pressure at different shear rates.
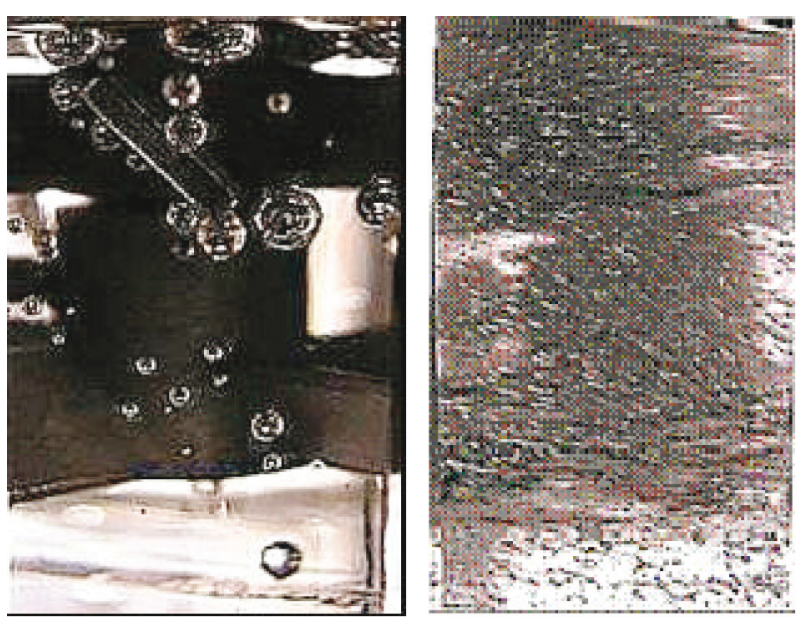

Figure 5

Pictures taken 30 minutes after the saturated silicon oil was depressurized instantaneously. Comparison between a depletion at rest (left) and under shear rate (right). the elongation of bubbles under shear. This could explain why the hard sphere model based on the spherical shape cannot describe anymore the viscosity of foamy oils under a high shear rate. As a result, the capillary number, $\mathrm{Ca}$, is often introduced to determine the impact of bubbles on the viscosity of a bubbly liquid. The capillary number is the ratio of the viscous forces, which tends to deform the bubble, to the surface tension that restores its spherical shape. It is written as follows:

$$
C a=\frac{\eta_{0} a \gamma}{\sigma}
$$

where $\eta_{0}$ is the viscosity of the continuous phase (Pa.s), $\sigma$ the gas/oil interfacial tension (estimated in our case from the measurement of an interface air/Canadian oil: $31 \mathrm{mN} / \mathrm{m}$ ) and $a$ the droplet radius. For high capillary numbers, bubbles are elongated and the viscosity of the bubbly liquid drops; for low $C a$, bubbles remain spherical and contribute to an increase in the material viscosity (Rust and Manga, 2002).

\subsection{Experiments with a Silicon Oil}

The previous experiments have been repeated with a transparent silicon oil $\left(8.5 \mathrm{~Pa} . \mathrm{s}\right.$ at $\left.28.5^{\circ} \mathrm{C}\right)$ instead of using the opaque black heavy crude oil. Figure 4 shows that this oil exhibits the same behaviour as the Canadian heavy oil during depletion.

Two additional equipments have been employed for the mineral oil: a pressurized reactor and a pressurized capillary rheometer. Both are fitted with a window which allows to visualize the foam morphology. In each case, methane is introduced under pressure (30 bars) until the mineral oil is saturated. Then, the system is depleted either at rest or under shear. Figure 5 presents the results obtained on the reactor. The picture on the left has been taken on the mineral oil 30 minutes after the depletion in quiescent conditions: bubbles are spherical and are not numerous. The picture on the right shows the same system but under shear: bubbles appear elongated and abundant. Under shear, bubbles are maintained much longer in the oil. One can oppose that this is due to our stirring geometry, impeding the bubbles from rising by disturbing the flow lines. In fact, it is not the case because we also observed the stability of elongated bubbles under simple shear.

To illustrate the opposite results obtained in quiescent and shearing conditions, the rising velocity of a bubble in a liquid has been considered. This velocity is given by the following relation (Stokes, 1851):

$$
V=\frac{2 g r^{2}\left(\rho_{L}-\rho_{G}\right)}{9 \eta_{L}}
$$

where $V$ is the velocity of the bubble, $g$ the gravitational acceleration, $r$ the bubble radius, $\rho_{L}$ and $\rho_{G}$ respectively the densities of the liquid and the gas phases and $\eta_{L}$ the viscosity of the liquid matrix. This relation does not fit the case of elongated bubbles as an additional friction term is being required for ellipsoids (Perrin, 1934, 1936). Thus the rising velocity appears to be lower when a bubble is elongated horizontally. This is a first explanation to the stability of bubbles in a flow. 
Experiments on the silicon oil have also been conducted using the Multipass Rheometer (MPR). The MPR is a pressurized capillary rheometer fitted with a window through which the sample can be visualized during the experiments. It has been developed in the Chemical Engineering Department of the University of Cambridge, UK (Mackley et al., 1995). The sample under study is driven back and forth through a capillary mid-section by hydraulic pistons. This arrangement allows control of the experimental shear rate or frequency, hydrostatic pressure and temperature. The viscosity is calculated from the pressure drop and the geometrical characteristics of the capillary tube. In addition, the use of specially designed capillaries allows optical birefringence, $\mathrm{X}$-ray measurements or direct visualization of the sample under test. Our results are presented in Figure 6.

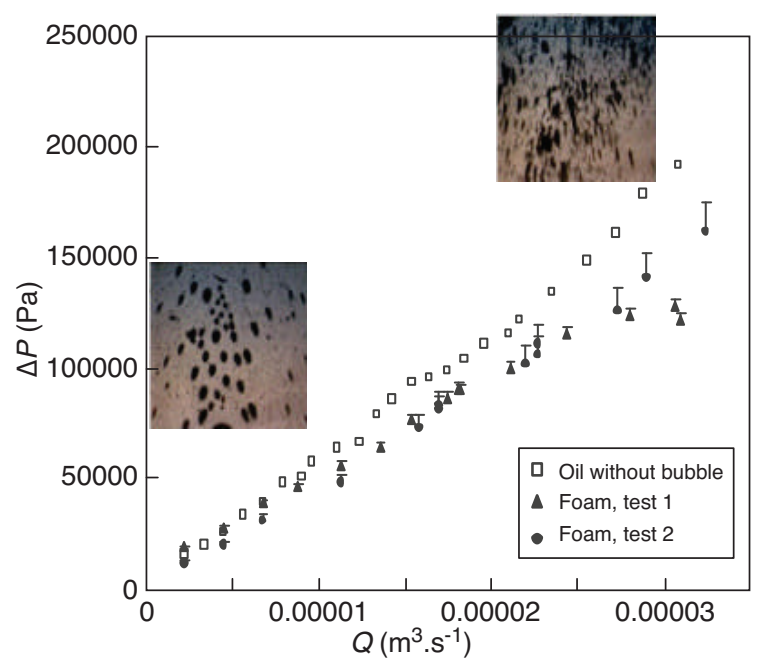

Figure 6

Pressure drop measured for the silicon oil and the silicon oil with bubbles (foam) in the MPR.

The pressure drop measured for the oil without any bubble is compared to the one obtained in the same conditions for the bubbly oil. It can be seen that the pressure drop is lower in the case of foams at high flow rates. Pictures taken during the experiments also show that bubbles are more and more elongated as the flow rate increases. Bubbles are $\mathrm{CO}_{2}$ added and mixed in the MPR. Thus the lower pressure drop measured in the case of foams is not due to the presence of dissolved gas in the matrix. These data support the assumption that the presence of elongated bubbles can lead to a decrease in the fluid apparent viscosity.

\subsection{Modelling of Bubbles Deformation}

To understand the effect of gas bubbles, and more specially their size, shape and orientation, on the average viscosity, we have computed the homogenized shear modulus of a model material in solid mechanics. The analogy between shear modulus and viscosity under low deformation is used here. Indeed, under low displacements, non linear terms of the Green-Lagrange strain tensor can be neglected and we obtain a linearized deformation tensor, which is similar to the one used in fluid mechanics.

We have considered a periodic representative cell and have applied an affine velocity field on the cell boundary. The averaged shear rates and shear stresses have then been computed, leading to an homogenized shear viscosity. For this calculation the finite element method was applied on the two configurations shown in Figure 7. As expected from our experimental results, the higher the bubble elongation in the flow direction, the lower the homogenized shear viscosity. In these simulations, we have ignored the effects of surface tension and we recognize that the analyzed configurations do not correspond exactly to the experimental observation, but in any case they allow to identify the evolution tendency and to confort, at least qualitatively, the rheological measurement results.

It has been shown in this section that the viscosity of a foamy oil highly depends on the shear conditions. The bubbles can lead to an increase in the viscosity if remaining spherical, while they can induce a drop in the apparent viscosity if elongated under sufficient shear rates. Thus the capillary number is an important characteristic of the studied system as it allows to predict the shape of the bubbles. In this work, the capillary number has been evaluated considering an average bubble diameter of $1 \mathrm{~mm}$, according to our visualizations. It is comprised between 2 and 20 for shear rates comprised between 10 and $100 \mathrm{~s}^{-1}$. Under the oscillatory tests, the capillary number can be evaluated at 0.01 at the maximum of deformation. These values are in accordance with Rust and Manga (2002), who found a critical capillary number around 0.7 above which the bubbles starts to elongate.

\subsection{Rising and Decreasing Viscosity Regimes}

The two flow regimes that have been previously described can be easily demonstrated by a particular experiment. It consists in depleting the system slowly (1 bar by stage every minute) instead of instantaneously. During all the experiment, the shear rate is set at $100 \mathrm{~s}^{-1}$. The viscosity ratio is plotted against the pressure in Figure 8. Its evolution can be described into three steps. First, an increase can be seen from 30 to 15 bars. This is due to the impoverishment of the matrix in dissolved gas and to the nucleation and growth of bubbles within the oil. At this stage, bubbles are small and remain spherical, contributing to an increase in the apparent 

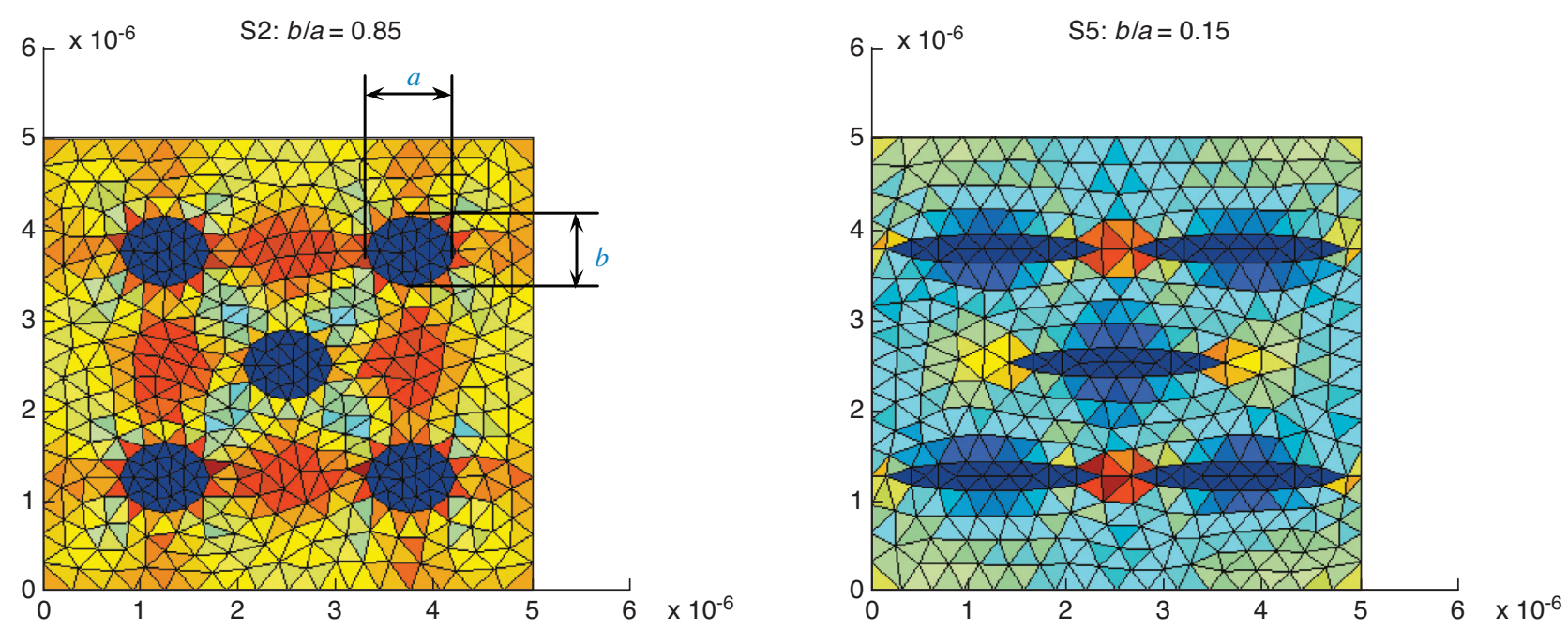

Figure 7

Modelling of the shear modulus of a material in the case of spherical holes and elongated holes.

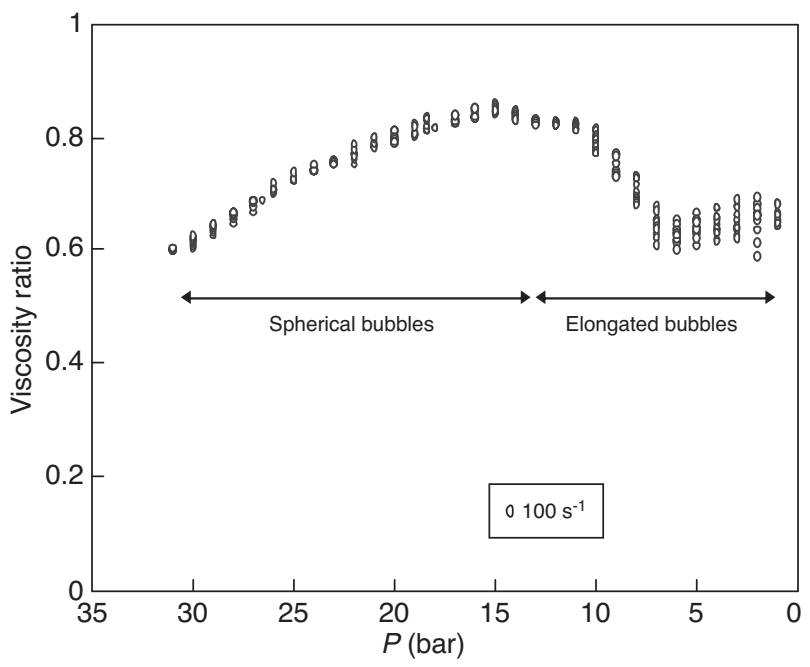

Figure 8

Depressurization of a saturated Canadian heavy oil from 30 bars to room pressure by 1 bar steps every minute.

viscosity. At $P=15$ bars, the viscosity starts to decline. The pressure still decreasing, the bubbles grow by diffusion of the dissolved gas towards the bubbles, by expansion and by coalescence. Since the bubbles are growing, they get deformable and begin to elongate. The flow regime is changing from a classical suspension model to a sandwichtype material. The viscosity is decreasing, despite the impoverishment of the oil in dissolved gas. At 7 bars, the system seems to have reached equilibrium. The apparent viscosity of the system is "stabilized" at a much lower value than the oil itself. So this figure depicts the two flow regimes described above: a regime where the viscosity rises with the presence of spherical bubbles and one where the viscosity drops, due to the elongation of the bubbles under shear.

\section{WATER-IN-OIL EMULSIONS}

In this part, the Canadian heavy crude oil behaviour has been investigated regarding the effect of added water content, droplet size, shear rate and temperature. The effect of pressure has also been studied (Chaudemanche et al.) but is out of scope of this paper.

To form water-in-oil emulsions, a $65 \mathrm{~mL}$ flask filled with heavy crude oil is placed in a water bath and heated at $40^{\circ} \mathrm{C}$ during $30 \mathrm{~min}$. Demineralised water is added, until the water/oil volume ratio desired is reached. The water volume percentage used $(\phi)$ varies from 0 to $30 \%$. A constant rotational speed is then applied with an Ultra-Turrax T25 to emulsify the water. Three different levels of mixing have been tested: 13 000, 19000 and $25000 \mathrm{rpm}$. Emulsions prepared with the highest one are the most stable. They have been kept at ambient temperature and have been further characterized by microscopy, calorimetry and rheological analysis.

\subsection{Microscopic Observation}

To determine the mean droplet size and the macroscopic structure associated to each water volume percentage, a sample of each emulsion has been analyzed under an optical 

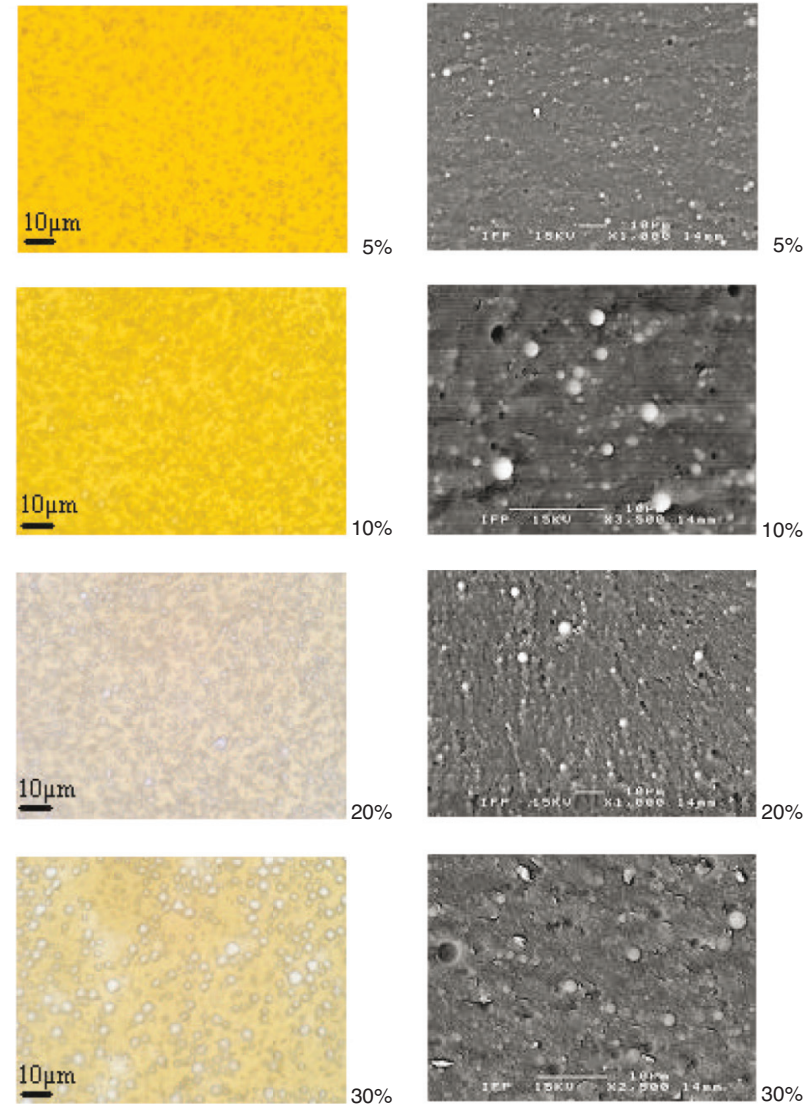

a) Optical microscope

b) Scanning electron microscope

Figure 9

Observation of $\mathrm{W} / \mathrm{O}$ emulsions under optical a) and scanning electron b) microscopes.

microscope and a cryogenic scanning electron microscope. Photomicrographs have been taken and the mean droplet size has been estimated. Figure 9 shows the micrographs of water-in-oil emulsions for $\phi=5,10,20$ and 30\%.

These micrographs depict the structure generated by the addition of water inside the heavy crude oil. Water droplets are clearly identified on both optical and electron microscopy. The mean droplet size is estimated as a function of the water volume percentage. The diameter is roughly similar whatever the water cut at $\sim 1 \mu \mathrm{m}$. However, the optical micrograph for a 30/70 W/O emulsion shows bigger droplets with a mean diameter of approximately $3 \mu \mathrm{m}$. Thus, an increase in water volume percentage seems to correspond with a slight increase in the mean droplet size. We assume that the increase in the mean droplet size is due to a lower available amount of natural surfactants. Actually, in all the experiments, the global volume is constant, meaning that when the water volume percentage increases, the oil content and its surfactant molecule content decreases accordingly. The main mechanism at the origin of bigger droplets, like coalescence, is favoured when asphaltene content is low. Indeed, it is well known that asphaltenes stabilize the water/oil interfaces and prevent coalescence (Sjöblom et al., 2003; Poteau et al., 2005).

These pictures also show that water droplets may form aggregates. This structure should be revealed by rheological analysis and could greatly influence the global behaviour of the emulsions under shear.

\subsection{Emulsion Characterisation by DSC}

Many techniques can be used to characterize emulsions, but most of them are not appropriate to dark and concentrated W/O emulsions. In order to avoid the dilution of these emulsions, which may create perturbation on the interactions between droplets, the microcalorimetry technique (Dalmazzone and Clausse, 2001) can be advantageously used. Differential Scanning Calorimetry is based on the measurement of heat exchanges between a sample and a reference as a function of time and temperature. The peak area of the recorded signal is related to the heat flow generated or absorbed by the sample. In the present work, each sample has been cooled from ambient temperature to $-100^{\circ} \mathrm{C}$, maintained 2 min at $-100^{\circ} \mathrm{C}$ and heated to $20^{\circ} \mathrm{C}$ at a constant scanning rate of $5^{\circ} \mathrm{C} / \mathrm{min}$. The water droplets, embedded inside the heavy crude oil, have thus crystallised during cooling and then have re-melted during heating. The crystallization temperature is correlated to the droplet size, whereas re-heating of the sample allows the determination of the water content.

The DSC thermograms of W/O emulsions, for $\phi=5,10$, 20 and 30\%, are presented in Figure 10. Results indicate that the samples analyzed are effectively W/O emulsions. The thermograms of each sample present one major crystallization peak at roughly $-40^{\circ} \mathrm{C}$, which is typical of a fine emulsion (Dalmazzone and Clausse, 2001). Practically no difference is observed on the crystallization temperatures as a function of the water volume percentage. The determination of the melting energy of the initial water sample allows the calculation of the water content of each emulsified sample from its corresponding melting energy (see Table 1). The experimental water content calculated is in accordance with the theoretical one.

\subsection{Steady State Flow Curves}

As already mentioned, the understanding of the rheological behaviour of emulsions is of importance, particularly for their transportation. It is a key point to determine viscosity as a function of the dispersed phase volume percentage. Through 


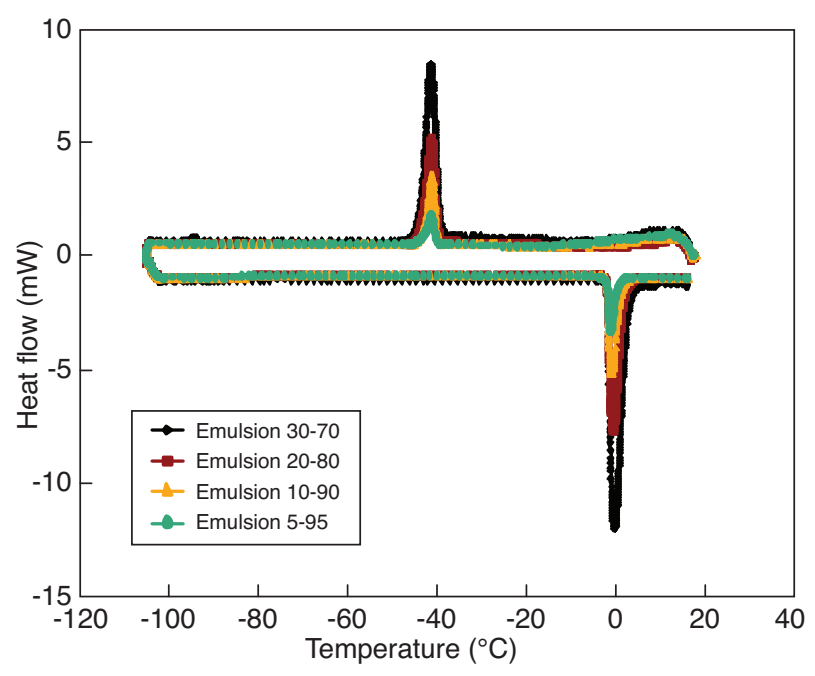

Figure 10

Thermograms of $\mathrm{W} / \mathrm{O}$ emulsions for $\phi=5,10,20$ and $30 \%$.

TABLE 1

Crystallization temperatures, melting/crystallization energies and experimental water content for $\phi=5,10,20,30$ and $100 \%$

\begin{tabular}{c|c|c|c|c}
\hline Sample & $\begin{array}{c}\text { Crystallization } \\
\text { temperature } \\
T_{\text {onset }}\left({ }^{\circ} \mathrm{C}\right)\end{array}$ & $\begin{array}{c}\text { Melting } \\
\text { energy } \\
(\mathrm{J} / \mathrm{g})\end{array}$ & $\begin{array}{c}\text { Crystallization } \\
\text { energy } \\
(\mathrm{J} / \mathrm{g})\end{array}$ & $\begin{array}{c}\text { Experimental } \\
\text { water content } \\
(\%)\end{array}$ \\
\hline $\begin{array}{c}\text { Distilled } \\
\text { water }\end{array}$ & -18.8 & 329.2 & 294.3 & 100 \\
\hline $5 / 95$ & -40.0 & 16.4 & 11.6 & 4.9 \\
\hline $10 / 90$ & -39.8 & 35.9 & 27.5 & 10.9 \\
\hline $20 / 80$ & -39.6 & 69.5 & 48.7 & 21.1 \\
\hline $30 / 70$ & -39.6 & 91.7 & 67.5 & 27.9 \\
\hline
\end{tabular}

the rheological analysis, we should be able to describe the structure associated with the increase of water volume percentage. In Figure 11, the viscosity measured at $40^{\circ} \mathrm{C}$ versus shear rate is plotted for each emulsion and compared to the heavy crude oil viscosity.

Viscosity $v s$. shear rate curves show a Newtonian behaviour for low shear rates. The Newtonian viscosity measured increases as the water volume percentage increases. Whatever the emulsion, viscosity decrease for shear rate higher than $100 \mathrm{~s}^{-1}$ is typical of a shear thinning behaviour. In the present work, shear viscosity curves have been fitted with a Williamson model:

$$
\eta=\frac{\eta_{0}}{1+(k \dot{\gamma})^{n}}
$$

where $\eta_{0}$ is the Newtonian viscosity of the emulsion (Pa.s), $k$ the consistency (s) and $n$ the rate index. The fitting parameters are given in Table 2. The $k$ parameter is equal to the inverse of a shear rate. This parameter increases with the water volume percentage, and indicates that the shear thinning behaviour occurs at lower shear rates. This tendency is consistent with microscopic observations, where the size and numbers of droplet aggregates increase with the water volume percentage.

TABLE 2

Parameters of the Williamson model for each emulsion studied

\begin{tabular}{c|c|c|c|c}
\hline & $5 / 95$ & $10 / 90$ & $20 / 80$ & $30 / 70$ \\
\hline$\eta_{0}$ (Pa.s) & 5.31 & 6.30 & 7.40 & 11.34 \\
\hline$k(\mathrm{~s})$ & $3.7110^{-4}$ & $1.9910^{-3}$ & $2.6510^{-3}$ & $5.6810^{-3}$ \\
\hline$n$ & 0.79 & 2.31 & 1.83 & 1.4 \\
\hline
\end{tabular}

These results are in accordance with measurements in the literature (Pal, 1996, 1997) where it is found that the droplet size may have a large impact on the viscosity, particularly when going to small droplet sizes. Pal $(1996,1997)$ argued a non-Newtonian behaviour such as shear thinning appeared to be more pronounced for fine than for coarse emulsions.

Different hypothesis can be formulated to explain the shear thinning behaviour. It may be due to shear-induced disruption of droplet aggregates and deformability of droplets (Saiki et al., 2007) or to the droplet break-up occurring for high hydrodynamic stress. To resolve this, the modelling of the rheological behaviour can be fruitful.

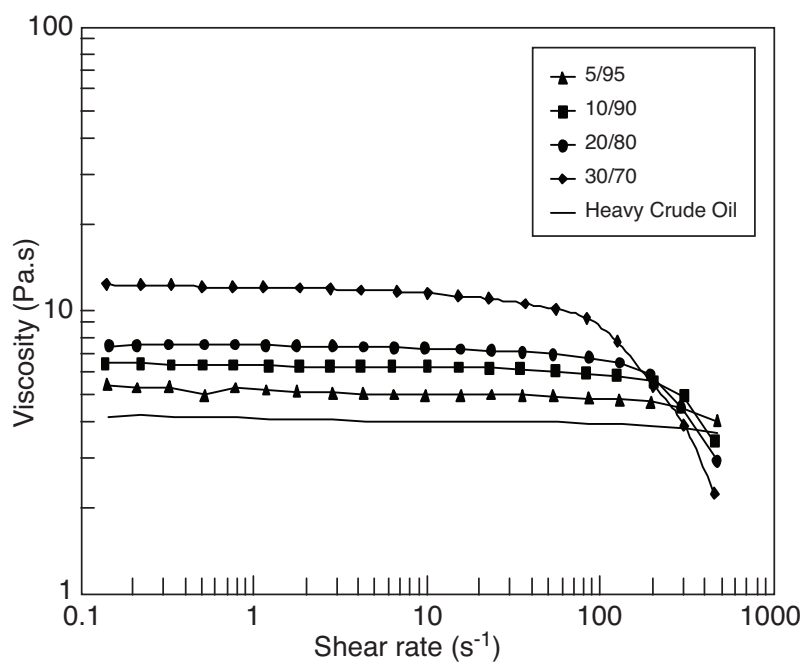

Figure 11

Flow curves for $\mathrm{W} / \mathrm{O}$ emulsions at $\phi=5,10,20$ and $30 \%$ and comparison with the Canadian heavy crude oil (Solid lines are Williamson approximations). 


\subsection{Modelling of the Flow Behaviour}

A large number of viscosity equations and correlations relating the emulsion viscosity to the dispersed phase volume percentage have been proposed in the literature. They all give expressions for the relative emulsion viscosity, $\eta_{r}$, i.e. the ratio of the emulsion viscosity $(\eta)$ to the pure continuous phase $\left(\eta_{c}\right)$ :

$$
\eta_{r}=\frac{\eta}{\eta_{c}}
$$

An overview of emulsion viscosity models and correlations was analyzed by Pal (2001) a few of them are mentioned here.

For very dilute emulsions, the viscosity is given by the following equation (Taylor, 1932):

$$
\eta_{r}=\frac{\eta}{\eta_{c}}=1+\left(\frac{\eta_{c}+2.5 \eta_{d}}{\eta_{c}+\eta_{d}}\right) \phi
$$

where $\eta_{d}$ is the viscosity of the dispersed phase (Pa.s).

In the limit of $\eta_{d} / \eta_{c} \rightarrow \infty$, Equation (3) reduces to the well-known Einstein equation (Einstein, 1906, 1911):

$$
\eta_{r}=1+2.5 \phi
$$

The Taylor equation cannot be applied when hydrodynamic interactions between the droplets become significant. In the emulsion literature, it is a common practice to apply suspension viscosity equations to interpret the viscosity/concentration behaviour (Saiki et al., 2007). Among the most widely used equations are:

- The Mooney equation (Mooney, 1951), which is an expression for the relative viscosity of dispersions of monodisperse spheres.

$$
\eta_{r}=\exp \left(\frac{2.5 \phi}{1-\phi / \phi_{m}}\right)
$$

- The Krieger and Dougherty equation (Krieger and Dougherty, 1959), which was developed for concentrated suspensions.

$$
\eta_{r}=\left(1-\phi / \phi_{m}\right)^{-2.5 \phi_{m}}
$$

In these last equations, $\phi_{m}$ is the maximum packing concentration of particles. At $\phi_{m}$, the viscosity of the suspension becomes infinite. The Krieger and Dougherty equation describes many suspension systems and has also been applied to emulsion systems (Tadros, 1994). Values expected concerning $\phi_{m}$ for suspensions are in the range: 0.64 (random close packing) to 0.74 (hexagonal close packing), but for emulsions larger $\phi_{m}$ were explained as being due to droplet polydispersity and deformation (Manoj et al., 1998). However, one serious drawback of applying these equations to emulsions is that these equations do not take into account the effect of viscosity ratio

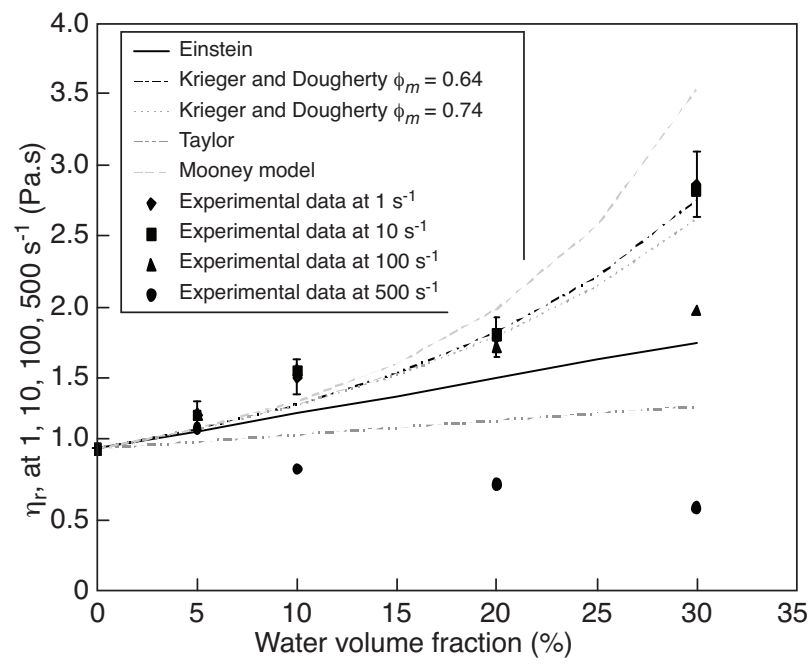

Figure 12

Relative viscosities vs. water volume percentage at $\dot{\gamma}=1,10$, 100 and $500 \mathrm{~s}^{-1}$, fitted with usual correlations.

$(K)$ between heavy oil and dispersed phase. In the case of bubbles, this parameter was not introduced because gas is considered to be inviscid.

The relative experimental viscosities, at four different shear rates $\left(1,10,100\right.$ and $\left.500 \mathrm{~s}^{-1}\right)$, plotted against the water volume percentage and fitted with the previous correlations are shown in Figure 12.

For these emulsions, the rheological behavior at low shear rates and low volume percentage can be approximated by the Einstein's equation for hard spheres, confirming previous works (Dickinson, 1998). At higher $\phi$, the Krieger and Dougherty model, with $\phi_{m}$ closed to 0.64 , fits with a good accuracy our experimental relative viscosities: water droplets can be considered as spherical. However, at higher shear rates (above $100 \mathrm{~s}^{-1}$ ) experimental relative viscosities can not be modelled by any correlations, as the models overestimate the emulsion viscosity. These results are in accordance with those found on water droplets deformation in alkyd resin (Thompson et al., 2001). The authors established that the viscosity reduction at high shear rates was due to an extensive distortion of the water droplets. To clarify this behaviour, it appears necessary to take into account the effect induced by shear stress on the droplet shape by the introduction of the capillary number as seen in the previous section for bubbles.

\subsection{Droplet Deformation}

The capillary number (Equation (1)) can also be used to determine the deformability of a droplet under shear rate. The degree of deformation $D$ can be described as a scalar combination of the lengths of the major $(L)$ and minor $(B)$ axes of 
an elliptical droplet (Taylor, 1932): $D=(L-B) /(L+B)$ and that for small deformations, $D$ is given by:

$$
D=C a\left(\frac{19 K+16}{16 K+16}\right)
$$

where $K$ is the viscosity ratio. Subsequent workers have extended the analysis applied by Taylor to transient flows (Cox, 1969), and extended the validity by performing the calculation to higher order in droplet deformation (Frankel and Acrivos, 1970). The following equation can thus estimate the level of droplet deformation (Torza et al., 1972):

$$
D=\frac{L-B}{L+B}=\frac{5(19 K+16)}{4(K+1) \sqrt{(20 / C a)^{2}+(19 K)^{2}}}
$$

Figure 13 shows the viscosity ratio between the emulsion viscosity and the Newtonian viscosity plotted against the droplet deformation at $40^{\circ} \mathrm{C}$. All curves, whatever the emulsion considered, can be superimposed. The beginning of the shear thinning behaviour can be thus described by the same parameter for each system noted $D_{\text {lim. }}$. This analysis was also carried out at $20,30,50$ and $60^{\circ} \mathrm{C}$ and no strong variation of $D_{\text {lim }}$ was noticed.

As the volume percentage rises, there is an increased possibility for droplets to experience deformation due to greater hydrodynamic forces and droplet collisions caused by shear. Deformation may allow droplets to slide on each other, leading to an emulsion less resistant to the applied shear, therefore less viscous, than the suspension at the same volume percentage.

A viscosity decrease with increasing disperse phase concentration is a well-known phenomenon for polymer blends. Viscosity reduction by more than that predicted on the basis of linear mixing has been attributed to slip between layers of polymer (Zhao and Macosko, 2000).

Experimentally, the critical capillary number $\left(\mathrm{Ca}_{\text {crit }}\right)$ necessary for break-up depends strongly on the viscosity ratio (Grace, 1982). If the viscosity ratio is very small, extreme deformation of the droplet is possible without inducing break-up in the steady state. The critical capillary number in simple shear is given by (Hinch and Acrivos, 1980):

$$
C a_{\text {crit }}=0.054 K^{-2 / 3}
$$

In the present work, according to Equation (11), $C a_{c r i t}$ is equal to approximately 15.8 . The capillary number calculated from $D_{\text {lim }}$, is $C a_{\text {lim }} \sim 0.6$. Thus, we argue that droplets do not break up, but deform into stretched droplets of elliptical cross section (see Fig. 14).

According to this schematic representation, a relaxation time should exist to allow droplets to recover their initial shape. To verify this hypothesis, a 30/70 water-in-oil emulsion has been submitted to an increasing shear rate from 0.1 to $500 \mathrm{~s}^{-1}$ followed by a decreasing shear rate from 500 to $0.1 \mathrm{~s}^{-1}$. This experiment is performed at 20,40 and $60^{\circ} \mathrm{C}$. The results are given in Figure 15. An hysteresis is observed

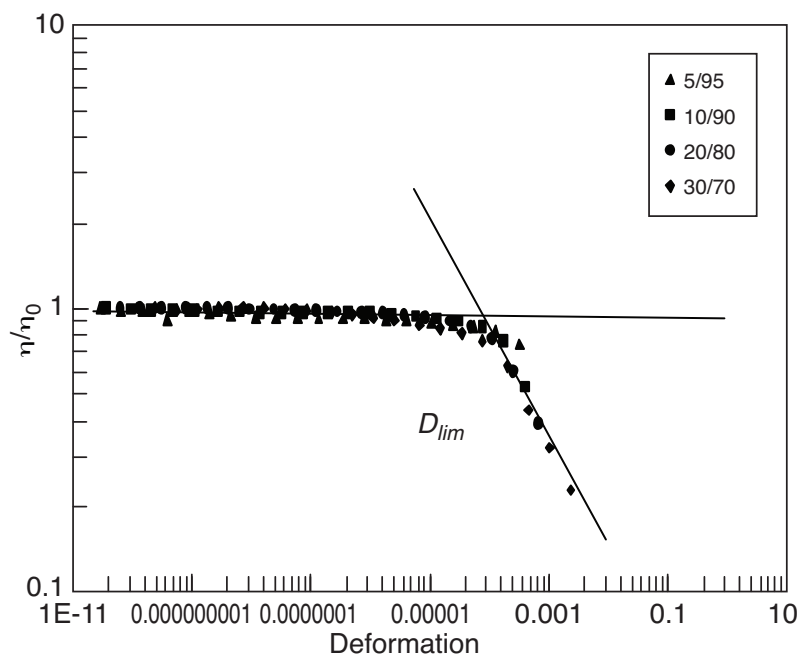

Figure 13

Viscosity ratio versus Deformation (according to Equation 9) for $\phi=5,10,20$ and $30 \%$.

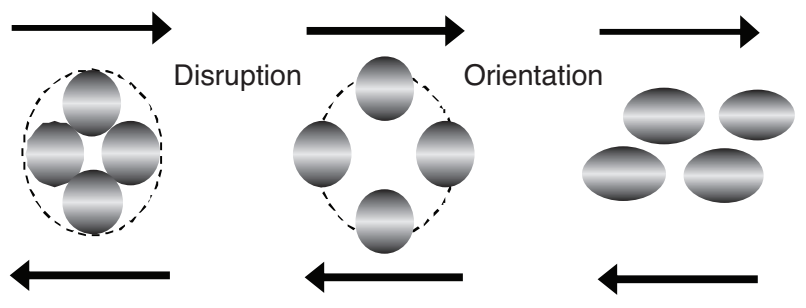

Figure 14

Schematic representation of the droplet disruption and orientation under shear.

whatever the temperature and is more emphasised as the temperature decreases. At low temperatures, the heavy crude oil viscosity is high and shear stresses transmitted to water droplets are promoted. Thus the relaxation time is higher when temperature falls, corresponding to highly stretched droplets. When the shear rate reaches $0.1 \mathrm{~s}^{-1}$, the final viscosity is approximately the same as the initial viscosity. This result is characteristic of a thixotropic behaviour.

In this second part, stable $\mathrm{W} / \mathrm{O}$ emulsions have been obtained with a mean droplet diameter $\sim 1 \mu \mathrm{m}$. By using DSC, we were able to confirm the water content and the nature of each emulsion prepared. The rheological analysis in the steady state proved that for low shear rates water droplets increase the emulsion viscosity. On the contrary, at high shear rates, the viscosities obtained were lower than those predicted by suspension and emulsion models, indicating the necessity to take into account the droplet deformation under shear. As in the case of deformed bubbles, elongated water droplets can lead to a strong decrease in viscosity of the fluid in which they are dispersed. 


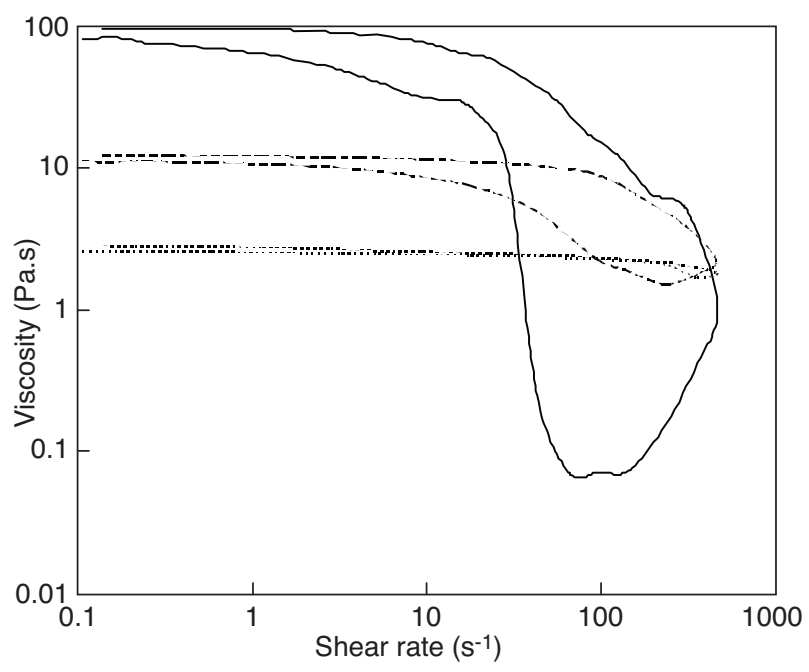

Figure 15

Emulsion viscosity $v s$. shear rate for $\phi=30 \%$ (solid line: $20^{\circ} \mathrm{C}$, dashed line: $40^{\circ} \mathrm{C}$ and dotted line: $60^{\circ} \mathrm{C}$ ).

\section{GAS BUBBLES AND WATER DROPLETS DISPERSED IN HEAVY CRUDE OILS}

In this part, several rheological experiments have been performed on the heavy crude oil containing both gas bubbles and water droplets. The objective is to show how flow properties of real multiphase system can be complex. As in the first section of this paper, bubbles have been created by depletion of a live emulsion. Again, the experiments are divided into two steps: the gas dissolution under shear and pressure followed by the appearance of bubbles provoked by depletion. The experiments have been carried out using both instantaneous and slow depletions from 30 bars to atmospheric pressure.

\subsection{Methane Dissolution}

The methane dissolution in the heavy crude oil and the emulsions is ensured by a helix geometry at 30 bars and $T=28.5^{\circ} \mathrm{C}$, under a shear of $100 \mathrm{~s}^{-1}$. The viscosity is measured as a function of time and we consider that the dissolution is achieved when the viscosity levels off, like in the first section of this paper. The dissolution of methane in water droplets is considered to be negligible (Berthezene et al., 1999). Thus the global solubility of methane is related to the oil volume percentage. To verify this hypothesis, we have fitted the viscosity of saturated emulsions with the wellknown Einstein model (Einstein, 1911). As seen in Figure 12 , it is quite suitable to predict emulsion viscosity at $100 \mathrm{~s}^{-1}$. The theoretical viscosities calculated with the Einstein model correspond to the experimental ones when the oil is saturated, thus confirming that the difference in viscosity is only due to the presence of spherical water droplets and not because methane is dissolved in water.

\subsection{Multiphase Dispersed Systems}

The rheological behaviour of a multiphase dispersed system, namely gas bubbles + water droplets embedded inside a heavy crude oil has been compared to the one of a system containing only bubbles.

Figure 16 presents the relative viscosity $\eta_{r}$ (i.e. system viscosity/emulsion viscosity at $\phi=0,10,20$ or $30 \%$ without bubbles at atmospheric pressure) during the depletion process under a continuous shear rate of $100 \mathrm{~s}^{-1}$. The experimental curves show that just like in the case of heavy oil, the foam obtained in emulsions has a relative viscosity stabilized at a value lower than 1 . The bubbly emulsion is therefore less viscous than the original emulsion. Again, this phenomenon is attributed to the elongation of the gas bubbles, favouring the liquid flow. The key point to highlight is that this phenomenon is influenced by water droplets. In fact, as in these conditions emulsions rich in water are more viscous, they deform more easily gas bubbles and enhance the viscosity drop.

In Figure 17, the evolution of the emulsion viscosity is plotted during a slow depletion at $1 \mathrm{bar} / \mathrm{min}$. The behaviour observed is totally different compared to an instantaneous depletion. We can observe in the first moment, a viscosity increase whatever the water volume percentage when the pressure has reached 27 bars. When the pressure is equal to 8 bars, the viscosity drops for each sample analyzed. This behaviour is characteristic of the presence of deformed gas bubbles. It seems that at this level of pressure, gas bubbles

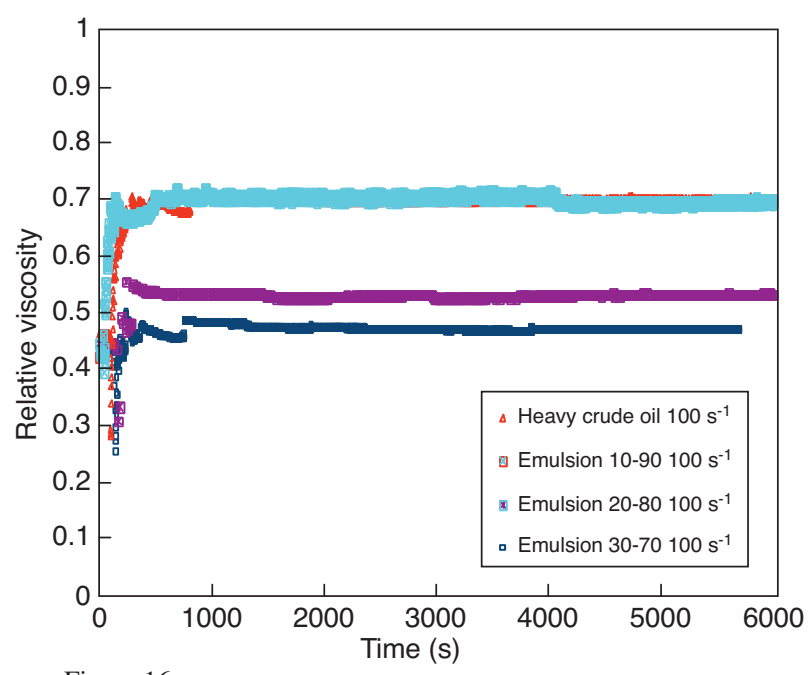

Figure 16

Evolution of the relative viscosity $v s$. time and pressure (depletion rate $=15 \mathrm{bars} / \mathrm{s}$ ) under a continuous shear rate of $100 \mathrm{~s}^{-1}$ for $\phi=0,10,20$ and $30 \%$. 


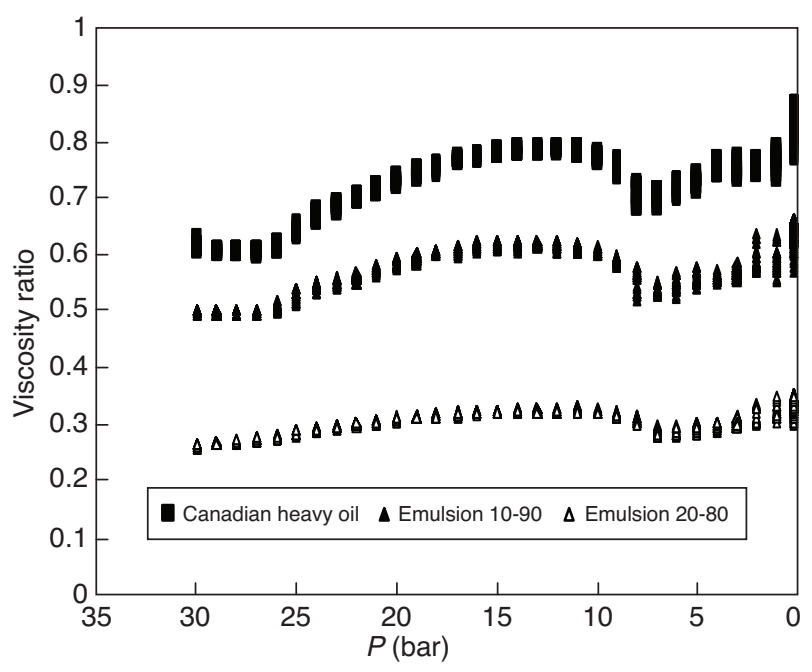

Figure 17

Evolution of the viscosity $v s$. time and pressure (depletion rate $=1 \mathrm{bar} / \mathrm{min}$ ) under a continuous shear rate of $100 \mathrm{~s}^{-1}$ for $\phi=0,10,20$ and $30 \%$.

are big enough (due to diffusion or coalescence) to allow their deformation under a constant shear rate. This enables to decrease the global viscosity of the multiphase system. Again, the decrease seems to be influenced by water droplets.

Spherical water droplets increase the viscosity of heavy oils and facilitate bubbles deformation, which in turn decreases viscosity. The case of elongated water droplets should be further studied. Unlike spherical bubbles, deformed ones lead to a decrease in viscosity, which does not promote bubble deformation. These remarks illustrate how rheological properties of mixed dispersed systems can be complex. It is particularly the case of bubbly live oil emulsions.

\section{CONCLUSIONS}

In this paper, it is demonstrated that the flow properties of heavy oils are highly modified by the presence of gas bubbles and water droplets. Naturally present within the oil during the production process, these dispersed phases can lead to either a decrease or an increase in heavy oil apparent viscosity, depending on the shear rates applied to the sample during its transport in the well or in the reservoir. Since bubbles and droplets are deformable, two flow regimes can be encountered. Under low shear rates, the suspended phases remain spherical. The material behaves like a classical dispersion and can be modelled in the limit of low volume percentages by a classical hard sphere model. In this case, the apparent viscosity of the produced oil is higher than the oil itself. Above a sufficient shear rate, the suspended phases are elongated in the flow line direction and the material behaves differently. We have shown that the viscosity is then lower than the crude oil itself. The deformability can thus lead to a decrease in the apparent suspension viscosity, what is of primary importance to predict the production rates of a well. It depends mainly on the viscosity ratio and the capillary number. That is why this phenomenon is fundamental in the case of heavy oils. Taking into account these qualitative results, a perspective would be to model the heavy oil viscosity in real conditions, like it is transported in the well.

\section{REFERENCES}

Abivin P., Hénaut I., Argillier J.-F., Moan M. (2008) Viscosity behavior of foamy oil: experimental study and modeling, Petrol. Sci. Technol. 26, 1545-1558.

Ait-Kadi A., Marchal Ph., Choplin L., Chrissemant A.-S., Bousmina M. (2002) Quantitative analysis of mixer-type rheometers using the Couette analogy, Can.J. Chem. Eng. 80, 6, 1166-1174.

Albartamani N.S. (2000) Experimental studies on "foamy oil" phenomena, Thèse de Doctorat, University of Alberta, Edmonton, AB, Canada.

Alboudwarej H., Muhammad M., Shakari A., Bubey S., Vreenegoor L., Saleh J. (2007) Rheology of heavy-oil emulsions, Presented at International Thermal Operations and Heavy Oil Symposium, Calgary, AB, Canada.

Bagdassarov N., Pinkerton H. (2003) Transient phenomena in vesicular lava flows based on laboratory experiments with analogue materials, J. Volcanol. Geoth. Res. 302, 1-22.

Bauget F. (2002) Production d'huiles lourdes par dépressurisation : études des interfaces huile-air et modélisation du procédé, Thèse de Doctorat, Université de Paris-Sud, Orsay.

Berthezene N., Hemptine J.-C. d., Audibert A., Argillier J.-F. (1999) Methane solubility in synthetic oil-based drilling muds, J. Petrol. Sci. Eng. 23, 71-81.

Bora R. (1998) Cold production of heavy oils: an experimental investigation of foamy oil flow in porous media, Thèse de Doctorat, University of Calgary.

Chaudemanche C., Hénaut I., Argillier J.-F. (to be published) Effect of pressure on rheological properties of water-in-crude oil emulsions. Claridge E.L., Prats M. (1995) A proposed model and mechanism for anomalous foamy heavy oil behaviour, SPE paper 29243.

Coustet-Pierre C. (2003) Caractérisation du comportement rhéologique des bruts lourds en vue de l'optimisation de leur transport, Thèse de Doctorat, Université de Bretagne Occidentale, Brest, France.

Cox R.G. (1969) The deformation of a drop in a general timedependent fluid flow, J. Fluid Mech.37, 601-623.

Dalmazzone C., Clausse D. (2001) Microcalorimetry, in Encyclopedic Handbook of Emulsion Technology, Sjöblom J. (ed.), Marcel Dekker, New-York.

Dickinson E. (1998) Rheology of emulsions - The relationship to structure stability, in Modern Aspects of Emulsion Science, Binks B. (ed.), The Royal Society of Chemistry, Cambridge, UK.

Einstein A. (1906) Eine neue Bestimmung der Moleküledimensionen, Ann. Phys.-Berlin 19, 289-306.

Einstein A. (1911) Berichtigung zu meiner Arbeit: eine neue Bestimmung der Moleküledimensionen, Ann. Phys.-Berlin 34, 591-592.

Fisher D.G., Espidel J., Huerta M., Randall L., Goldman J. (1999) Use of magnetic resonance imaging as a tool for the study of foamy oil behaviour for an extra-heavy crude oil, Transport Porous Med. 35, 189-204. 
Frankel N.A., Acrivos A. (1970) The constitutive equation for a dilute emulsion, J. Fluid Mech. 44, 65-78.

Goodarzi N., Bryan J., Mai A., Kantzas A. (2005) Heavy-oil fluid testing with conventional and novel techniques, Presented at SPE International Thermal Operations and Heavy Oil Symposium, Calgary, AB, Canada.

Grace H.P. (1982) Dispersion phenomena in high viscosity immiscible fluid systems and application to static mixers as dispersion devices in such systems, Chem. Eng. Commun. 14, 225-227.

Henriot V., Duret E., Heintze E., Courbot A. (2002) Multiphase production control: application to slug flow, Oil Gas Sci. Technol. 57, 1, 87-98.

Hinch E.J., Acrivos A. (1980) Long slender drops in a simple shear flow, J. Fluid Mech. 98, 305-328.

Huerta M., Otero C., Rico A., Jimenez I., Mirabal M.d., Rojas G. (1996) Understanding foamy oil mechanisms for heavy oil reservoirs during primary production, SPE paper 36749.

Islam M.R., Chakma A. (1990) Mechanics of bubble flow in heavy oil reservoirs, SPE paper 20070.

Krieger I.M., Dougherty T.J. (1959) A mechanism for nonNewtonian flow in suspensions of rigid spheres, J. Rheol. 3, 1, 137-152.

Llewellin E.W., Mader H.M., Wilson S.D.R. (2002) The rheology of a bubbly liquid, Proc. R. Soc. A 458, 20, 987-1016.

Loughead D., Saltuklaroglu M. (1992) Lloydminster heavy oil production - why so unusual? Presented at 9th Annual Heavy Oil and Oil Sand Symposium, Calgary, AB, Canada.

Mackley M.R., Marshall R.T.J.,. Smeulders J.B.A.F. (1995) The multipass rheometer, J. Rheol. 39, 6, 1293-1309.

Maini B.B., Sarma H.K., George A.E. (1993) Significance of foamy oil behaviour in primary production of heavy oils, J. Can. Petrol. Technol. 32, 9 .

Manga M., Loewenberg M. (2001) Viscosity of magmas containing highly deformable bubbles, J. Volcanol. Geoth. Res. 105, 19-24.

Manoj P., Watson A.D., Hibbert D.J., Fillery-Davis A.J., Robins M.M. (1998) Characterization of a depletion-flocculated polydisperse emulsion II. Steady state rheological investigation, J. Colloid Interf. Sci. 207, 294-302.

Mooney M. (1951) The viscosity of a concentrated suspension of spherical particles, J. Colloid Sci. 6, 162-170.

Pal R. (1996) Effect of droplet size on the rheology of emulsions, AIChE J. 42, 11, 3181-3190.

Pal R. (1997) Scaling of relative viscosity of emulsions, J. Rheol. 41, 1, 141-150.

Pal R. (2001) Novel viscosity equations for two immiscible liquids, J. Rheol. 45, 2 .

Perrin F. (1934) Mouvement Brownien d'un ellipsoïde. I. Dispersion diélectrique pour des molécules ellipsoïdales, J. Phys. Radium. 7, 497-511.

Perrin F. (1936) Mouvement Brownien d'un ellipsoïde. II. Rotation libre et dépolarisation des fluorescences, Translation et diffusion de molécules ellipsoïdales, J. Phys. Radium. 7, 1-11.

Poteau S., Argillier J.-F., Langevin D., Pincet F., Perez E. (2005) Influence of $\mathrm{pH}$ on stability and dynamic properties of asphaltenes and other amphiphilic molecules at the oil-water interface, Energ. Fuel. 19, 1337-1341.
Renard G., Nauroy J.-F., Deruyter C., Moulu J.-C., Sarda J.-P., Le Romancer J.-F. (2000) Production froide des huiles visqueuses, Oil Gas Sci.Technol. 55, 35-66.

Rust A.C., Manga M. (2002) Effects of bubble deformation on the viscosity of dilute suspensions, J. Non-Newton. Fluid 104, 53-63.

Saiki Y., Prestidge A., Horn R.G. (2007) Effects of droplet deformability on emulsion rheology, Colloid. Surface. A 299, 1, 65-72.

Sheng J.J., Maini B.B., Hayes R.E., Tortike W.S. (1999) Critical review of foamy oil flow, Transport Porous Med. 35, 157-187.

Singh P., Thomason W.H., Gharfeh S., Nathanson L.D., Blumer D.J. (2004) Flow properties of Alaskan heavy-oil emulsions, Presented at SPE Annual Technical Conference and Exhibition, Houston, TX, USA.

Sjöblom J., Aske N., Auflem I.H., Brandal O., Havre T.E., Saether O., Westvik A., Johnsen E.E., Kallevik H. (2003) Our current understanding of water-in-crude oil emulsions: Recent characterization techniques and high pressure performance, Adv. Colloid Interfac. 100-102, 399-473.

Smith G.E. (1988) Fluid flow and sand production in heavy oil reservoirs under solution-gas drive, SPE Prod. Eng. 3, 2, 169-180.

Stein D.J., Spera F.J. (2002) Shear viscosity of rhyolite vapor emulsions at magmatic temperatures by concentric cylinder rheometry, $J$. Volcanol. Geoth. Res. 113, 243-258.

Stokes G.G. (1851) On the effect of the Internal Friction of Fluidson the motion of Pendulums, Camb. Philos. Trans. 9, 8-106, 1851.

Szelag H., Pauzder B. (2003) Rheological properties of emulsions stabilized by acylglycerol emulsifiers modified with dodium carboxylates, Colloid. Surface. A 219, 87-95.

Tadros T.F. (1994) Fundamentals principles of emulsion rheology and their applications, Colloid. Surface. A 91, 39-55.

Taitel Y. (1986) Stability of severe slugging, Int. J. Multiphas. Flow 12, 2, 203-217.

Taylor G.I. (1932) The viscosity of a fluid containing small drops of another fluid, Proc. R. Soc. Lond. 138, 834, 41-48.

Thompson M.J., Pearson J.R.A., Mackley M.R. (2001) The effect of droplet extension on the rheology of emulsions of water in alkyd resin, J. Rheol. 45, 6, 1341-1358.

Torza S., Cox R.G., Mason S.G. (1972) Particule motions in sheared suspensions XXVII. Transient and steady deformation and burst of liquid drops, J. Colloid Interf. Sci. 38, 395-411.

Tuladhar T.R., Mackley M.R. (2005) The development of polymer foam microstructure: experimental observations and matching modelling for polystyrene foams using different blowing agent, Presented at 7th World Congress of Chemical Engineering, Glasgow, Scotland.

Weatherhill B.D., Seto A.C., Gupta S.K., Cobo L. (2005) Cold heavy oil production at Patos, -Marinza, Albania, Presented at SPE International Thermal Operations and Heavy Oil Symposium Calgary, AB, Canada.

Zhao R., Macosko C.W. (2000) Rheology of immiscible polymer blends - interfacial slip, Presented at XIII International Congress on Rheology, Cambridge, UK.

Final manuscript received in July 2008 Published online in February 2009

Copyright (C) 2009 Institut français du pétrole

Permission to make digital or hard copies of part or all of this work for personal or classroom use is granted without fee provided that copies are not made or distributed for profit or commercial advantage and that copies bear this notice and the full citation on the first page. Copyrights for components of this work owned by others than IFP must be honored. Abstracting with credit is permitted. To copy otherwise, to republish, to post on servers, or to redistribute to lists, requires prior specific permission and/or a fee: Request permission from Documentation, Institut français du pétrole, fax. +33147527078 , or revueogst@ifp.fr. 